\title{
CHILD SERVICES
}

Harry Marsh explains how Contact a Family links carers of children with the local services that can help them.

USEFUL INFORMATION

Contact a Family 170 Tottenham Court Road London W1P OHA

Tel: 01713833555

Fax: 01713830259
C ontact a Family is a national charity, founded in 1979, with the aims of: promoting mutual support between families caring for children with disabilities, providing information to such families, and acting as a public voice on matters of concern to the carers of disabled children.

Contact a Family's early work included a number of communitybased projects in London and the west of England.

Several of those community projects are still in operation and each year they deliver a programme of activities (such as summer playschemes, family outings, and information days) and advise parents on such matters as education, benefits, holidays and much more.

\section{HELPLINE}

At national level, the charity currently provides a number of services for individual parents and for parents' groups.

These services include a national helpline, which is staffed by three experienced parent advisers who respond to some 7,000 inquiries a year on a wide range of topics.

Many parents want to know the details of their nearest local parents' group or relevant organisations. Other parents wish to have background information on specific conditions - and there are many hundreds of those - or on matters like genetic counselling, education, and remedial therapies.

Contact a Family's parent advisers also provide a one-to-one linking service for parents who wish to contact another family.
For many parents of children with special needs, the best source of emotional support and practical information comes through membership of a local self-help group. Often started by parents, they can range from a core of local mums having coffee mornings through to large networks of parents who run information evenings or successfully influence the delivery of local services. Contact a Family's national and regional development officers have links with many such groups across the country.

In addition, Contact a Family has two senior national development officers who give advice, support and training to a wide range of parents' groups which focus on specific conditions, ranging from Addison's disease at the beginning of the alphabet to West syndrome at the end. This area of activity includes a particular service to those groups covering disorders which affect children's life expectancy.

\section{USEFUL PUBLICATIONS}

Contact a Family publishes a range of material, including the quarterly journal 'Share an idea' (£10 a year), a number of factsheets and reports, and the widely acclaimed 'Contact a Family directory of specific conditions and rare syndromes in children with their family support networks'.

Contact a Family is actively engaged with the Carers Alliance (a consortium of voluntary organisations promoting the welfare of carers) and the Carers National Association in presenting the case, to the public, press and Parliament, for better support for parent carers. 